\title{
Mutation Profile Variability in the Primary Tumor and Multiple Pulmonary Metastases of Clear Cell Renal Cell Carcinoma. A Review of the Literature and Analysis of Four Metastatic Cases
}

\author{
Kristyna Prochazkova ${ }^{1}$, Nikola Ptakova ${ }^{2}$, Reza Alaghehbandan ${ }^{3}$, Sean R. Williamson ${ }^{4}{ }^{\mathbb{D}}$, Tomáš Vaněček ${ }^{5}$, \\ Josef Vodicka $\left.{ }^{1}{ }^{(}\right)$, Vladislav Treska ${ }^{1}$, Joanna Rogala ${ }^{5}{ }^{(D}$, Kristyna Pivovarcikova ${ }^{5}$, Kvetoslava Michalova ${ }^{5}$, \\ Maryna Slisarenko ${ }^{5}$, Milan Hora ${ }^{6}$, Michal Michal ${ }^{5}$ and Ondrej Hes ${ }^{5, *}$
}

1 Department of Surgery, Faculty of Medicine in Pilsen and University Hospital Pilsen, Charles University, 30460 Pilsen, Czech Republic; Prochazkovak@fnplzen.cz (K.P.); vodicka@fnplzen.cz (J.V.); treska@fnplzen.cz (V.T.)

2 Second Faculty of Medicine, Charles University, 15006 Prague, Czech Republic; ptakova@biopticka.cz

3 Department of Pathology, University of British Columbia, Vancouver, BC 2329, Canada; Reza.Alaghehbandan@fraserhealth.ca

4 Robert J. Tomsich Pathology and Laboratory Medicine Institute and Glickman Urological Institute, Cleveland Clinic, Cleveland, OH 44195, USA; williamson.sean@outlook.com

check for

updates

Citation: Prochazkova, K.; Ptakova, N.; Alaghehbandan, R.; Williamson, S.R.; Vaněček, T.;

Vodicka, J.; Treska, V.; Rogala, J.; Pivovarcikova, K.; Michalova, K.; et al. Mutation Profile Variability in the Primary Tumor and Multiple Pulmonary Metastases of Clear Cell Renal Cell Carcinoma. A Review of the Literature and Analysis of Four Metastatic Cases. Cancers 2021, 13, 5906. https://doi.org/10.3390/ cancers13235906

Academic Editors: José I. López and Claudia Manini

Received: 21 September 2021 Accepted: 22 November 2021 Published: 24 November 2021

Publisher's Note: MDPI stays neutral with regard to jurisdictional claims in published maps and institutional affiliations.

Copyright: (c) 2021 by the authors. Licensee MDPI, Basel, Switzerland. This article is an open access article distributed under the terms and conditions of the Creative Commons Attribution (CC BY) license (https:/ / creativecommons.org/licenses/by/ $4.0 /)$.
5 Department of Pathology, Faculty of Medicine in Pilsen and University Hospital Pilsen, Charles University, 30599 Pilsen, Czech Republic; vanecek@bioptica.cz (T.V.); superrrogalik7@gmail.com (J.R.);

Pivovarcikova@fnplzen.cz (K.P.); Kvetoslava.Michalova@biopticka.cz (K.M.); MarynaSlisarenko@gmail.com (M.S.); Michal@biopticka.cz (M.M.)

6 Department of Urology, Faculty of Medicine in Pilsen and University Hospital Pilsen, Charles University, 30599 Pilsen, Czech Republic; horam@biopticka.cz

* Correspondence: hes@biopticka.cz

Simple Summary: Clear cell renal cell carcinoma (CCRCC) is well known for intra-tumoral heterogeneity. However, there are limited data focusing on the inter-tumoral and inter-metastatic heterogeneity of CCRCC. In one study, primary and metastatic tumors were classified as clear cell type A or B subtypes, using nanostring expression technology. It was found that primary and metastatic tumors of CCRCC differed in nearly one half of patients. Approximately one quarter of metastatic tumors display inter-metastatic heterogeneity. Another study, using an immunohistochemical assay, found inter-metastatic tumor heterogeneity of BAP1 in only 1 of 32 patients $(3 \%)$. Comparing gene expression across patient-matched primary-metastatic tumor pairs, $98 \%$ had concordant BAP1 status. We aimed to review published data and to examine mutation profile variability in primary and multiple pulmonary metastases (PMs) in our cohort of four patients with metastatic CCRCC.

Abstract: (1) Background: There are limited data concerning inter-tumoral and inter-metastatic heterogeneity in clear cell renal cell carcinoma (CCRCC). The aim of our study was to review published data and to examine mutation profile variability in primary and multiple pulmonary metastases (PMs) in our cohort of four patients with metastatic CCRCC. (2) Methods: Four patients were enrolled in this study. The clinical characteristics, types of surgeries, histopathologic results, immunohistochemical and genetic evaluations of corresponding primary tumor and PMs, and followup data were recorded. (3) Results: In our series, the most commonly mutated genes were those in the canonically dysregulated VHL pathway, which were detected in both primary tumors and corresponding metastasis. There were genetic profile differences between primary and metastatic tumors, as well as among particular metastases in one patient. (4) Conclusions: CCRCC shows heterogeneity between the primary tumor and its metastasis. Such mutational changes may be responsible for suboptimal treatment outcomes in targeted therapy settings.

Keywords: clear cell renal cell carcinoma; intra-tumoral heterogeneity; inter-tumoral heterogeneity; inter-metastatic heterogeneity 


\section{Introduction}

Clear cell renal cell carcinoma (CCRCC) is the most common renal carcinoma, accounting for more than $70 \%$ of adult renal cancer [1,2]. Nonsurgical therapy for metastatic RCC (mRCC) has limited efficacy, with a median overall survival (OS) of 26.4-32.0 months [2]. The lung is one of the most affected metastatic sites in patients with CCRCC. If clinically feasible, metastasectomy is preferable for metastatic disease [3]. The 5 year survival rates after a complete pulmonary metastasectomy range from 36 to $83 \%$ [4].

CCRCC is well known for intra-tumoral heterogeneity [2,5-10] and morphologic, immunohistochemical and genetic differences also exist between the primary tumor and its metastases (inter-tumoral heterogeneity) [11-14]. Furthermore, heterogeneity among multiple metastases in a single patient (inter-metastatic heterogeneity) has been reported [11,14].

$V H L, B A P 1, P B R M 1$, and SETD2 are the most frequently mutated genes, all located on chromosome $3 p$. Chromosome arm $3 p$ loss is a common event in primary CCRCC, and in difficult diagnostic pathology cases, molecular evaluation can be used to support a diagnosis of CCRCC, such as chromosome $3 p$ loss (FISH, cytogenetics, or copy number analysis) or VHL mutational analysis. However, $3 p$ loss may not be entirely specific for clear cell RCC in all contexts [15]. For example, chromosome $3 p$ loss has been recognized in subsets of papillary RCC, unclassified RCC, and RCC with the amplification of the 6 p21/TFEB gene region, including in tumors with non-clear cell morphology and without VHL alterations [16-18]. Although the majority of CCRCCs show mutation in the VHL gene, LOH3p, or the hypermethylation status of VHL gene, $25-30 \%$ of CCRCCs show other molecular genetic changes [2]. The molecular study of the Cancer Genome Atlas Research Network identified 19 significantly mutated genes, with alterations of VHL, PBRM1, SETD2, KDMC, PTEN, BAP1, MTOR and TP53, being the eight most frequent [2,19].

CCRCC is ideal for studying intra-tumoral heterogeneity, since adjuvant therapy is not standard practice [3]. Therefore, the effect of therapy on the development of resistance or tumor changes can be excluded. The aim of this review was to summarize the current knowledge on intra-tumoral, inter-tumoral, and inter-metastatic heterogeneity in CCRCC at the morphologic, immunohistochemical, and molecular-genetic levels.

\subsection{Morphology and Immunohistochemistry \\ 1.1.1. Intra-Tumoral Heterogeneity}

López et al. [5] drew attention to the problem of tumor sampling, particularly in CCRCC where some large tumors may display areas with different colors and/or textures on gross sections. It is worth noting that even neoplastic cell populations in CCRCC, which may seem homogenous microscopically, indeed may be very heterogeneous at the molecular level with different mutation profiles in different parts of the tumor [6]. In routine clinical practice, more than $95 \%$ of the tissue of a given $10 \mathrm{~cm}$ tumor is not analyzed, when following typical sampling protocols (i.e., one block per 1-2 cm of the tumor). In these cases, the histo-molecular data that might be derived from non-sampled areas of the tumor are lost. Therefore, some authors suggest that a multisite tumor sampling approach would be more informative than routine sampling [6,7].

CCRCC is typically immunoreactive for PAX8, PAX2, pankeratin (AE1-AE3), CAM5.2, and epithelial membrane antigens. Carbonic anhydrase 9 (CA9) is positive in a diffuse membranous pattern in $75-100 \%$ of CCRCC; however, high-grade tumors may exhibit a reduced immunohistochemical expression [2]. According to the latest edition of the WHO classification of genitourinary tumors, keratin 7 positivity in CCRCC is only seen in isolated cells, in rare high-grade tumors, and is often used to distinguish CCRCC from chromophobe RCC [2]. However, in a recent study by Gonzalez et al. examining keratin 7 reactivity in a spectrum of 75 CCRCC tumors, it was shown that low-grade CCRCCs were more frequently positive than high-grade tumors [8]. 


\subsubsection{Inter-Tumoral Heterogeneity}

Eckel-Passow and colleagues analyzed the immunohistochemical expression of BAP1 and PBRM1 in primary and metastatic tumors from 97 patients. In their cohort, $20 \%$ of primary tumors showed the loss of BAP1 staining and 57\% showed the loss of PBRM1. They demonstrated subtle molecular heterogeneity in the metastatic tumors with similar morphology. Comparing expression across patient-matched primary-metastatic tumor pairs, the authors reported that $98 \%$ had concordant BAP1 status (90\% PBRM1). Only two patients demonstrated discordant BAP1 immunohistochemical expression, with the loss of BAP1 during the progression to metastatic disease [11].

\subsubsection{Inter-Metastatic Heterogeneity}

Eckel-Passow et al. [11] also determined the inter-metastatic tumor heterogeneity of BAP1 using immunohistochemical examination. However, they found heterogeneity of BAP1 in only 1 patient in a cohort of 32 patients (3\%). The primary tumor for this patient was BAP1 positive, whereas the first bone metastasis was IHC negative, and the second bone metastasis) was IHC positive. In this study, the authors also examined intra-metastatic tumor heterogeneity, and found a $100 \%$ concordance in BAP1 between 12 patients. The limitation of this study was that the expression was determined using an immunohistochemical assay only, with no further molecular genetic validation.

\subsection{Molecular Genetic Analysis}

\subsubsection{Intra-Tumoral Heterogeneity}

Gerlinger et al. analyzed material from four tumors (core biopsy) in four patients with metastatic CCRCC. They demonstrated intra-tumoral heterogeneity for a mutation within an auto-inhibitory domain of the mTOR kinase. Mutational intratumoral heterogeneity was found for multiple tumor suppressor genes resulting in a loss of function. Multiple distinct mutations of SETD2, PTEN, and KDM5C genes were found within a single tumor [9].

In their subsequent study, the authors showed that ultra-deep sequencing identified intra-tumoral heterogeneity in all cases. Using multiregional exome sequencing, the authors reported the following as the most prevalent mutations: PBRM1 60\%, SETD2 30\%, BAP1 $40 \%$, KDM5C 10\%, TP53 40\%, ATM 10\%, ARID1A 10\%, PTEN 20\%, MTOR 10\%, PIK3CA $20 \%$, and TSC2 $10 \%$. The combined prevalence of the indicated PI3K-mTOR pathway genes (PTEN, PIK3CA, TSC2, MTOR) was up to $60 \%$ [10].

\subsubsection{Inter-Tumoral Heterogeneity}

According to Serie et al. [14], heterogeneity between primary and distant simultaneous metastases affects half of the patients with metastatic CCRCC. The authors analyzed primary CCRCC and their metastases using nanostring technology. Nanostring assays were successful in 91 primary tumors and 123 metastases from different organs, most frequently from the lung. ClearCode 34 genes were also analyzed for all tumors. They divided primary and secondary tumors into so-called ccA and ccB subtypes, based on the proposed stratification by Brooks et al. [12]. They further compared ccA/ccB subtypes across patientmatched primary and metastatic CCRCC tumors and documented discordance in $43 \%$ of patients.

\subsubsection{Inter-Metastatic Heterogeneity}

Serie et al. [14] also evaluated inter-metastatic tumor heterogeneity. Thirty patients in their cohort had more than one metastatic tumor. Seven of the $30(23 \%)$ had metastatic tumors with discordant $\mathrm{cc} \mathrm{A} / \mathrm{ccB}$ subtypes.

\section{Materials and Methods}

Pulmonary metastasectomy for metastatic CCRCC (single or multiple metastases) was performed in 35 patients (without evidence of local residual disease, recurrence, or any disease other than pulmonary metastases) in a single academic institution (Department of 
Surgery, University Hospital in Pilsen) from January 2001 to January 2019. From this cohort, 13 patients had undergone multifocal surgical treatments for their pulmonary metastases of CCRCC. Four patients were excluded from our study since the primary tumor was not available. Five patients were later excluded from the study because of low DNA quality. Finally, four cases were selected and enrolled into the study.

The following clinical and pathologic characteristics were obtained: gender, age at diagnosis, tumor size, pathologic stage [20], histologic grade (ISUP/WHO) [2], progressionfree interval (PFI is defined as the time period between curative primary kidney surgery and the first detection of metastatic disease), pulmonary metastases details (site, size of the largest metastasis, synchronous or metachronous, number, and laterality), the type of pulmonary surgery, histopathology results, the type of adjuvant therapies, and follow-up data.

The primary tumor was diagnosed based on morphology and the immunohistochemical (IHC) profile. The tissues were processed as published previously [21]. The following primary antibodies were used: keratin 7 (OV-TL12/30, monoclonal, DakoCytomation, 1:200), vimentin (D9, monoclonal, NeoMarkers, Westinghouse, CA, USA, 1:1000), carbonic anhydrase 9 (rhCA9, monoclonal, R\&D Systems, Abingdon, GB, USA, 1:100), PD-L1 (22C3, monoclonal, Cell Signaling, Danvers, MA, USA, 1:25), and Ki67 (MIB1, monoclonal, Dako, Glostrup, Denmark, 1:1000). The primary antibodies were visualized using a supersensitive streptavidin-biotin-peroxidase complex (BioGenex, Fremont, CA, USA). Internal biotin was blocked by the standard protocol used by the Ventana BenchMark XT automated stainer (hydrogen peroxide-based). Appropriate positive and negative controls were applied. The immunohistochemical evaluation was based on the staining percentage of cells: focal positive $<50 \%$, diffuse positive $>50 \%$, and negative (-) $0 \%$. For the PD-L1 antibody, a total $\%$ of positive neoplastic cells and \% of intervening stromal cells and lymphocytes was recorded.

\subsection{Mutation Analysis}

A mutation analysis detection of tumor and non-tumor tissue was performed using a TruSight Oncology 500 (TSO500) panel (Illumina, San Diego, CA, USA) [22]. In two cases, data from the TruSight Tumor 170 panel (TS170) (Illumina) were used for samples with low DNA quality. The gene list was previously published [23]. Total nucleic acid was extracted using an FFPE DNA kit (automated on an RSC 48 Instrument, Promega, Madison, WI, USA). Purified DNA was quantified using a Qubit Broad Range DNA assay (Thermo Fisher Scientific, Waltham, MA, USA). The quality of DNA was assessed using the FFPE QC kit (Illumina). DNA samples with $\mathrm{Cq}<5$ were used for further analysis. After DNA enzymatic fragmentation with a KAPA Frag Kit (Kapa Biosystems, Washington, MA, USA), DNA libraries were prepared with the TSO500/TS170 (Illumina) according to the manufacturer's protocol. Sequencing was performed on the NextSeq 500 sequencer (Illumina) following the manufacturer's recommendations. A data analysis was performed using the TSO500/TS170 application on the BaseSpace Sequence Hub (Illumina). DNA variant filtering and annotation were performed using the cloud-based tool Variant Interpreter (Illumina). A custom variant filter was set up including only variants with coding consequences at an allelic frequency of $5 \%$ and higher. The cut-off was set at $1 \%$ only in the case of mutations known in related tumor tissue. Comparing tumor and non-tumor data, germline alterations were excluded. The remaining subset of variants was checked visually, and suspected artefactual variants were excluded.

\subsection{Analysis of VHL Promoter Methylation}

The detection of promoter methylation was carried out via methylation-specific PCR as previously described [24]. 


\section{3. $\mathrm{LOH}$ Analysis}

For an LOH analysis of neoplastic tissue DNA, ten STR (short tandem repeats) markers D3S666, D3S1270, D3S1300, D3S1581, D3S1597, D3S1600, D3S1603, D3S1768, D3S2338 and D3S3630 located on the short arm of chromosome 3 (3p) were chosen from the database (Gene Bank UniSTS) [25].

\section{Results}

Four patients were enrolled in the study. Clinicopathologic data are summarized in Table 1. The patients were two men and two women, with ages ranging from 53.6 to 67.4 years (mean 61.5, median 62.5 years) at the time of renal surgery. Radical nephrectomy was performed in three cases. In one case, nephron sparing surgery was performed, but during the follow-up period, radical nephrectomy was completed due to recurrence (after a period of 72.6 months). Tumor size ranged from $30 \mathrm{~mm}$ to $75 \mathrm{~mm}$ (mean 53.5, median 54.5). The pathologic stage included $1 \times$ pT2a, $1 \times$ pT3a, and $2 \times$ pT1a. At the time of diagnosis, one patient had synchronous pulmonary lesions. The median progression-free interval (PFI) of the other cases was 40.5 months.

The mean age at the time of pulmonary metastasectomy was 65.5 years. Two patients had bilateral lung metastases, which were resected in a multistage fashion in independent surgeries. Overall, nine metastases were removed (in three patients, there were two metastases; in one patient, there were three metastases).

Signs of aggressive behavior were found approximately 2 to 35 months after pulmonary metastasectomy (metastatic progression to bones, lung, mediastinum, lymph nodes, and brain; median PFI was 18.7). Follow-up data were available for all patients, ranging approximately from 88 to 123 months (mean 104.4, median 103.4 months). For brain metastasis, surgical treatment using a gamma knife was performed. However, this patient died of peritonitis 3 months after the brain surgery. One patient died from the progression of the disease to the lung and bone 6 years after pulmonary surgery. To date, one patient with a progression of disease after 2 months (lymphatic tissue, bones, kidney) and one patient with a progression of disease 35 months (lymph nodes) after pulmonary surgery are alive.

Table 1. Primary tumors: clinicopathological features.

\begin{tabular}{ccccc}
\hline & Patient 1 & Patient 2 & Patient 3 & Patient 4 \\
\hline Sex & $\mathrm{F}$ & $\mathrm{M}$ & $\mathrm{M}$ & $\mathrm{F}$ \\
Age (years) & 61.6 & 67.4 & 63.4 & 53.6 \\
Size (mm) & 39 & 75 & 30 & 70 \\
pT (UICC 2017) & $\mathrm{pT1a}$ & $\mathrm{pT2a}$ & $\mathrm{pT} 1 \mathrm{a}$ & $\mathrm{pT3b}$ \\
Grade (WHO/ISUP) & 3 & 2 & 2 & 2 \\
TTP meta 1 & 40.5 & $\mathrm{M} 1$ & 59.6 & 38.1 \\
TTP meta 2 & 40.5 & $\mathrm{M} 1$ & 81.1 & 38.1 \\
TTP meta 3 & - & - & 81.1 & \\
F, female; M, male; M1, M1 stage (pulmonary metastases at the time of the renal cancer diagnosis); TTP, time to \\
pulmonary progression (months).
\end{tabular}

\subsection{Morphology}

All cases showed morphologic features typical of CCRCC. Primary tumors were arranged in a solid alveolar pattern, and occasionally with smaller cystic areas. The rich vasculature characteristic of CCRCC was noted in all primary tumors. Only small foci of necrosis or regressive changes were recorded. Neoplastic cells were mostly voluminous with clear to pale eosinophilic cytoplasm. The histologic grade was 2 in three tumors and 3 in one tumor. Metastases showed relatively uniform morphology, arranged mostly in solid architecture and composed of predominantly clear cells. The histologic grade was 2 in 8/9 metastatic foci and 3 in 1/9 metastases (Table 2). 
Table 2. Grade of the primary tumors and metastases.

\begin{tabular}{ccccc}
\hline & Patient $\mathbf{1}$ & Patient 2 & Patient 3 & Patient $\mathbf{4}$ \\
\hline Primary tumor grade & 3 & 2 & 2 & 2 \\
Met 1 grade & 2 & 2 & 3 & 2 \\
Met 2 grade & 2 & 2 & 2 & 2 \\
Met 3 grade & & & 2 & \\
\hline Met, metastasis. & &
\end{tabular}

Met, metastasis.

\subsection{Immunohistochemical Analysis}

All primary tumors and metastases were positive for CA9 (diffuse strong positivity) and vimentin. The Ki-67 proliferation index ranged from 3-12 positive cells/high-power field (under $10 \%$ ). Primary tumors and metastases were negative for keratin 7 .

The primary tumor and metastases were immunohistochemically examined using BAP1 antibody. Except for one tumor (patient 4), all primary tumors were BAP1 negative. In patient 3, negative BAP1 in the primary tumor and positive BAP1 in two of three PMs were documented.

PD-L1 reactivity was evaluated in all available samples. Only one primary tumor showed significant positivity (up to $30 \%$ of neoplastic cells); however, no positivity was documented in the available tissue from pulmonary metastasis (Table 3).

Table 3. PD-L1 reactivity in the primary tumor and metastases.

\begin{tabular}{|c|c|c|c|c|}
\hline PD-L1 & Case 1 & Case 2 & Case 3 & Case 4 \\
\hline Primary tumor & $\begin{array}{l}* 0 \% \\
* * 0 \%\end{array}$ & $\begin{array}{l}{ }^{*} 0 \% \\
* * 0 \%\end{array}$ & $\begin{array}{c}* \text { up to } 5 \% \\
* * 0 \%\end{array}$ & $\begin{array}{l}* 30 \% \\
* * 0 \%\end{array}$ \\
\hline Met 1 & NA & $\begin{array}{l}* 0 \% \\
* * 0 \%\end{array}$ & $\begin{array}{c}* 0 \% \\
* * \text { up to } 5 \%\end{array}$ & $\begin{array}{l}* 0 \% \\
* * 0 \%\end{array}$ \\
\hline Met 2 & $\begin{array}{l}* \text { up to } 5 \% \\
* * 0 \%\end{array}$ & $\begin{array}{l}* 0 \% \\
* * 0 \%\end{array}$ & NA & NA \\
\hline Met 3 & & & NA & \\
\hline
\end{tabular}

\subsection{Molecular Genetic Analysis}

Results of the molecular genetic analysis are summarized in Table 4. Typical VHL gene alterations were found in three primary tumors and their PMs (75\%). In the patient without VHL mutation, we found alterations in CUL3, DOT1L, SETD2 and TSC1 in the primary tumor, with the addition of BAP1 gene mutation in its analyzable PMs.

The comparison of mutation pattern among primary tumors and their PMs showed heterogeneity in three $(75 \%)$ cases. In one case (patient 1), inter-metastatic differences were also found. In one metastasis, the mutation of GNAQ and loss of LOH3p were detected; however, in the second metastasis those changes were not confirmed. The comparison is displayed in Table 5.

Table 4. Mutational profile of primary tumors and their PMs using TSO500/TS170 panels.

\begin{tabular}{|c|c|c|c|c|}
\hline & Gene & Protein ID:Protein Alteration & Transcript ID: Mutation & Allele Frequency \\
\hline \multirow{6}{*}{$\begin{array}{c}\text { Patient } 1 \text { - primary tumor } \\
\text { TMB }-6.5\end{array}$} & MSH6 & NP_000170.1:p.(Ala780Ser) & NM_000179.2:c.2338G>T & 0.2586 \\
\hline & MYOD1 & NP_002469.2:p.(Glu158Lys) & NM_002478.4:c.472G>A & 0.2071 \\
\hline & PBRM1 & NP_060783.3:p.(Tyr893Ter) & NM_018313.4:c.2679T>A & 0.2885 \\
\hline & SETD2 & NP 054878.5:p.(Lys2471Ile) & NM 014159.6:c.7412A > T & 0.3654 \\
\hline & TFE3 & NP_006512.2:p.(Pro374Ala) & NM_006521.5:c.1120C>G & 0.2237 \\
\hline & VHL & NP_000542.1:p.(Ser65Ter) & NM_000551.3:c.194C>A & 0.3855 \\
\hline
\end{tabular}


Table 4. Cont.

\begin{tabular}{|c|c|c|c|c|}
\hline & Gene & Protein ID:Protein Alteration & Transcript ID: Mutation & Allele Frequency \\
\hline \multirow{7}{*}{$\begin{array}{c}\text { Patient } 1 \text { - metastasis } 1 \\
\text { TMB-5.5 }\end{array}$} & BCORL1 & NP_001171701.1:p.(Pro787Thr) & NM_001184772.2:c.2359C>A & 0.2074 \\
\hline & MSH6 & NP_000170.1:p.(Ala780Ser) & NM_000179.2:c. $2338 \mathrm{G}>\mathrm{T}$ & 0.256 \\
\hline & MYOD1 & NP_002469.2:p.(Glu158Lys) & NM_002478.4:c.472G>A & 0.256 \\
\hline & PBRM1 & NP_060783.3:p.(Tyr893Ter) & NM_018313.4:c.2679T >A & 0.2657 \\
\hline & SETD2 & NP 054878.5:p.(Lys2471Ile) & NM 014159.6:c.7412A > T & 0.2372 \\
\hline & TSC1 & NP_000359.1:p.(Glu839Ter) & NM_000368.4:c.2515G>T & 0.3039 \\
\hline & VHL & NP 000542.1:p.(Ser65Ter) & NM 000551.3:c.194C >A & 0.2896 \\
\hline \multirow[t]{4}{*}{ Patient $1-$ metastasis 2} & MSH 6 & NP_000170.1:p.(Ala780Ser) & NM_000179.2:c.2338G > T & 0.30 \\
\hline & TSC1 & NP_000359.1:p.(Glu839Ter) & NM_000368.4:c.2515G>T & 0.39 \\
\hline & VHL & NP 000542.1:p.(Ser65Ter) & NM 000551.3:c.194C>A & 0.40 \\
\hline & GNAQ & NP_002063.2:p.(Tyr101Ter) & NM_002072.4:c.303C>A & 0.08 \\
\hline \multirow[t]{6}{*}{$\begin{array}{c}\text { Patient 2-primary tumor } \\
\text { TMB-4.7 }\end{array}$} & CDK12 & NP_057591.2:p.(Leu529PhefsTer81) & NM_016507.2:c.1585del & 0.1264 \\
\hline & PTEN & & NM_000314.6:c.492+1del & 0.2 \\
\hline & $R E L$ & NP_002899.1:p.(Ser274Cys) & NM_002908.3:c.821C>G & 0.0685 \\
\hline & SETD2 & NP 054878.5:p.(Gly1467ArgfsTer8) & NM 014159.6:c.4398dup & 0.105 \\
\hline & TGFBR2 & NP_001020018.1:p.(Glu510Asp) & NM_001024847.2:c.1530A >C & 0.0857 \\
\hline & VHL & & NM_000551.3:c.463+2T >A & 0.1091 \\
\hline \multirow{6}{*}{$\begin{array}{c}\text { Patient } 2-\text { metastasis } 1 \\
\text { TMB }-6.3\end{array}$} & CDK12 & NP_057591.2:p.(Leu529PhefsTer81) & NM_016507.2:c.1585del & 0.0993 \\
\hline & PTEN & & NM_000314.6:c.492+1del & 0.2207 \\
\hline & $R E L$ & NP_002899.1:p.(Ser274Cys) & NM_002908.3:c.821C>G & 0.1138 \\
\hline & SETD2 & NP 054878.5:p.(Gly1467ArgfsTer8) & NM 014159.6:c.4398dup & 0.1229 \\
\hline & TGFBR2 & NP_001020018.1:p.(Glu510Asp) & NM_001024847.2:c.1530A >C & 0.15 \\
\hline & VHL & & NM_000551.3:c.463+2T>A & 0.1044 \\
\hline \multirow{6}{*}{$\begin{array}{c}\text { Patient } 2-\text { metastasis } 2 \\
\text { TMB }-7.1\end{array}$} & CDK12 & NP_057591.2:p.(Leu529PhefsTer81) & NM_016507.2:c.1585del & 0.0989 \\
\hline & PTEN & & NM_000314.6:c.492+1del & 0.2308 \\
\hline & $R E L$ & NP_002899.1:p.(Ser274Cys) & NM_002908.3:c.821C>G & 0.1059 \\
\hline & SETD2 & NP 054878.5:p.(Gly1467ArgfsTer8) & NM 014159.6:c.4398dup & 0.1365 \\
\hline & TGFBR2 & NP_001020018.1:p.(Glu510Asp) & NM_001024847.2:c.1530A>C & 0.0856 \\
\hline & VHL & & NM_000551.3:c.463+2T >A & 0.0828 \\
\hline \multirow{4}{*}{$\begin{array}{c}\text { Patient 3-primary tumor } \\
\text { TMB }-4.7\end{array}$} & CUL3 & NP_001244127.1:p.(Val452PhefsTer9) & NM_001257198.1:c.1354del & 0.1523 \\
\hline & DOT1L & NP_115871.1:p.(Met147Ile) & NM_032482.2:c.441G>T & 0.1664 \\
\hline & SETD2 & NP_054878.5:p.(Gln2070Ter) & NM_014159.6:c.6208C>T & 0.1696 \\
\hline & TSC1 & NP_000359.1:p.(Asn364LysfsTer5) & NM_000368.4:c.1091dup & 0.195 \\
\hline \multirow{5}{*}{$\begin{array}{c}\text { Patient } 3 \text {-metastasis } 1 \\
\text { TMB }-4.7\end{array}$} & BAP1 & NP_004647.1:p.(Arg385Ter) & NM_004656.3:c.1153C>T & 0.1193 \\
\hline & CUL3 & NP_001244127.1:p.(Val452PhefsTer9) & NM_001257198.1:c.1354del & 0.1127 \\
\hline & DOT1L & NP_115871.1:p.(Met147lle) & NM_032482.2:c.441G>T & 0.1032 \\
\hline & SETD2 & NP_054878.5:p.(Gln2070Ter) & NM_014159.6:c.6208C >T & 0.1191 \\
\hline & TSC1 & NP_000359.1:p.(Asn364LysfsTer5) & NM_000368.4:c.1091dup & 0.0714 \\
\hline \multirow{5}{*}{$\begin{array}{c}\text { Patient } 3-\text { metastasis } 2 \\
\text { TMB }-4\end{array}$} & BAP1 & NP_004647.1:p.(Arg385Ter) & NM_004656.3:c.1153C>T & 0.1026 \\
\hline & CUL3 & NP_001244127.1:p.(Val452PhefsTer9) & NM_001257198.1:c.1354del & 0.1076 \\
\hline & DOT1L & NP_115871.1:p.(Met147lle) & NM_̄032482.2:c.441G>T & 0.0642 \\
\hline & SETD2 & NP_054878.5:p.(Gln2070Ter) & NM_014159.6:c.6208C>T & 0.1177 \\
\hline & TSC1 & NP_000359.1:p.(Asn364LysfsTer5) & NM_000368.4:c.1091dup & 0.0559 \\
\hline \multirow{4}{*}{$\begin{array}{c}\text { Patient 4-primary tumor } \\
\text { TMB-3.1 }\end{array}$} & ARID5B & NP_115575.1:p.(Ala954Asp) & NM_032199.2:c.2861C >A & 0.0835 \\
\hline & BAP1 & NP_004647.1:p.(Gly703SerfsTer30) & NM_004656.3:c.2107_2116del & 0.1046 \\
\hline & VHL & NP_000542.1:p.(Arg69AlafsTer82) & NM_000551.3:c.201_225del & 0.0917 \\
\hline & XIAP & NP_001158.2:p.(Ser169Tyr) & NM_001167.3:c.506C >A & 0.0583 \\
\hline \multirow{3}{*}{$\begin{array}{c}\text { Patient } 4-\text { metastasis } 1 \\
\text { TMB-1.6 }\end{array}$} & ARID5B & NP_115575.1:p.(Ala954Asp) & NM_032199.2:c.2861C>A & 0.0835 \\
\hline & $B A P 1$ & & NM_004656.3:c.122+1G>T & 0.0806 \\
\hline & VHL & NP_000542.1:p.(Arg69AlafsTer82) & NM_000551.3:c.201_225del & 0.0718 \\
\hline \multirow[t]{2}{*}{ Patient 4 -metastasis 2} & BAP1 & & NM_004656.3:c.122+1G>T & 0.03 \\
\hline & VHL & NP_000542.1:p.(Arg69AlafsTer82) & NM_000551.3:c.201_225del & 0.06 \\
\hline
\end{tabular}


Table 5. The genetic profile of primary tumors and their PMs.

\begin{tabular}{|c|c|c|c|c|c|c|c|c|c|c|c|c|c|}
\hline & $\begin{array}{l}\text { Patient } 1 \\
\text { Primary } \\
\text { Tumor }\end{array}$ & $\begin{array}{c}\text { Patient } 1 \\
\text { Metas- } \\
\text { tasis } 1\end{array}$ & $\begin{array}{c}\text { Patient } 1 \\
\text { Metas- } \\
\text { tasis } 2\end{array}$ & $\begin{array}{c}\text { Patient } 2 \\
\text { Primary } \\
\text { Tumor }\end{array}$ & $\begin{array}{c}\text { Patient } 2 \\
\text { Metas- } \\
\text { tasis } \\
1\end{array}$ & $\begin{array}{c}\text { Patient } 2 \\
\text { Metas- } \\
\text { tasis } 2\end{array}$ & $\begin{array}{c}\text { Patient } 3 \\
\text { Primary } \\
\text { Tumor }\end{array}$ & $\begin{array}{c}\text { Patient } 3 \\
\text { Metas- } \\
\text { tasis } 1\end{array}$ & $\begin{array}{l}\text { Patient } 3 \\
\text { Metas- } \\
\text { tasis } 2\end{array}$ & $\begin{array}{l}\text { Patient } 3 \\
\text { Metas- } \\
\text { tasis } 3\end{array}$ & $\begin{array}{c}\text { Patient } 4 \\
\text { Primary } \\
\text { Tumor }\end{array}$ & $\begin{array}{c}\text { Patient } 4 \\
\text { Metas- } \\
\text { tasis } 1\end{array}$ & $\begin{array}{c}\text { Patient } 4 \\
\text { Metas- } \\
\text { tasis } 2\end{array}$ \\
\hline \multicolumn{14}{|l|}{ ARID5B } \\
\hline \multicolumn{14}{|l|}{ BAP1 } \\
\hline \multicolumn{14}{|l|}{ BCORL1 } \\
\hline \multicolumn{14}{|l|}{ CDK12 } \\
\hline \multicolumn{14}{|l|}{ CUL3 } \\
\hline \multicolumn{14}{|l|}{$\overline{D O T 1 L}$} \\
\hline \multicolumn{14}{|l|}{ GNAQ } \\
\hline \multicolumn{14}{|l|}{ MSH6 } \\
\hline \multicolumn{14}{|l|}{ MYOD1 } \\
\hline \multicolumn{14}{|l|}{ PBRM1 } \\
\hline \multicolumn{14}{|l|}{ PTEN } \\
\hline \multicolumn{14}{|l|}{ REL } \\
\hline \multicolumn{14}{|l|}{ SETD2 } \\
\hline \multicolumn{14}{|l|}{ TFE3 } \\
\hline \multicolumn{14}{|l|}{ TGFBR2 } \\
\hline \multicolumn{14}{|l|}{ TSC1 } \\
\hline \multicolumn{14}{|l|}{ VHL } \\
\hline \multicolumn{14}{|l|}{ XIAP } \\
\hline \multicolumn{14}{|l|}{ VHL } \\
\hline VHL $M$ & & & & & & & & & & & & & \\
\hline & & $\begin{array}{l}\text { non-sense } \\
\text { missense } \\
\text { splice-site } \\
\text { not analyz } \\
\mathrm{LOH} \text {-los } \\
\mathrm{LOH} \text {-los } \\
\mathrm{LOH} \text {-los } \\
\mathrm{M}-\text { prom } \\
\mathrm{M} \text { - prom }\end{array}$ & $\begin{array}{l}\text { nutation } \\
\text { utation } \\
\text { nutation } \\
\text { ble } \\
\text { of heteroz } \\
\text { of heteroz } \\
\text { of heterozy } \\
\text { ter methyl } \\
\text { ter methyl }\end{array}$ & $\begin{array}{l}\text { gosity-pos } \\
\text { gosity-nes } \\
\text { gosity-bor } \\
\text { ion-posit } \\
\text { ion-negat }\end{array}$ & $\begin{array}{l}\text { tive } \\
\text { tive } \\
\text { lerline } \\
\text { e } \\
\text { ve }\end{array}$ & & & & & & & & \\
\hline
\end{tabular}

\section{Discussion}

The loss of the short arm of chromosome 3 in CCRCC is a ubiquitous somatic event, accompanied by the inactivation of the remaining $V H L$ gene through mutation or methylation (in $>90 \%$ ) [26-29].

The VHL gene product (pVHL) is a component of E3 ubiquitin ligase complex, a key regulator of the cellular response to hypoxia. The E3 ubiquitin ligase complex promotes the degradation of its substrates including the alpha subunit of the hypoxia inducible factor $(\mathrm{HIF} \alpha)$. The loss of $V H L$ results in the accumulation of HIF- $\alpha$, leading to the constitutive expression of HIF target genes. These genes are involved in angiogenesis (e.g., VEGF), glycolysis and glucose transport (e.g., GLUT1), and erythropoiesis (e.g., EPO), which molecularly characterize CCRCC [30,31]. Mutations in other members of the E3 ubiquitin ligase complex such as elongin C (ELOC/TCEB1) and cullin 2 (CUL2) occur rarely and are mutually exclusive to $V H L$. Although there are differences between tumors with mutations in TCEB1 and VHL, the dysregulation of the VHL pathway may explain the overlapping morphology and immunohistochemical profile [32].

Chromosome $3 p$ loss may be identified using different molecular genetic methods. This and the mutation or promoter hypermethylation of $V H L$ are so common in CCRCC that a subset of tumors without such alterations may be misclassified [33]; however, the usage of extensive molecular testing is rare in current clinical practice. Varying driver gene alterations underpin CCRCC evolution and biology [34,35]. CCRCCs with VHL loss as the only driver event are indolent and rarely metastasize.

The loss of $3 p$ results in the simultaneous loss of three other tumor suppressor genes that are frequently mutated in CCRCC: Polybromo 1 (PBRM1) $(\sim 50 \%)$, SET domain containing 2 (SETD2) ( 20\%), and BRCA1-associated protein 1 (BAP1) ( 15\%) [26,32,36]. It should be noted that tumorigenesis in CCRCC follows a trunk-branch evolution [37], in which the trunk mutation $(V H L)$ is responsible for tumorigenesis and sub-clonal mutations (i.e., PBRM1, SETD2, BAP1) are developed during disease progression.

Similar to $V H L, P B R M 1$ is often mutated early during tumor development [38]. PBRM1-mutated tumors with subsequent SETD2 mutations, driver somatic copy number 
alterations, or P13K pathway alterations have a more attenuated disease course [36,37,39]. In contrast, CCRCCs with BAP1 mutations or multiple driver mutations are associated with aggressive clinical behavior and early metastatic disease. Additional driver mutations and somatic copy number alterations include (i) inactivating mutations in histone modifying genes (KDM5C and KDM6A), (ii) mutations in the mTOR pathway genes (TSC1, TSC2, MTOR, PIK3CA, PTEN), (iii) the loss of TP53, and (iv) losses of chromosomes 14 and $9[26,34,40]$.

Recent large scale gene expression analyses of metastatic CCRCC identified unique molecular subsets with distinct drug response characteristics [38,41]. CCRCC with high angiogenic gene signatures had a favorable response to anti-angiogenic therapies and were enriched with PBRM1 loss $[35,41]$. In contrast, CCRCCs with an inflamed microenvironment were associated with the highest PD-L1 expression, preferential responsiveness to regimes containing immune checkpoint inhibitors and the highest rates of sarcomatoid change and BAP1 mutations [38,39,41].

Passow et al. [11] also showed inter-metastatic tumor heterogeneity in BAP1 immunohistochemical reactivity in their study. The primary tumor in their study was BAP1 IHC positive, the first bone metastasis (synchronous) was IHC negative, and the second bone metastasis (diagnosed approximately 9 months later) was BAP1 IHC positive. In our study, we also observed variability in BAP1 immunohistochemical reactivity. In one of our cases (no. 3), the primary tumor and one of its metastases (PM3) were both BAP1 negative, whereas its two other distant metastases (PM1, PM2) were BAP1 positive. Of note, these IHC findings were consistent with the mutation analysis. BAP1 IHC expression also perfectly matched with the mutation profile in our fourth case, although two different BAP1 mutations were unexpectedly found in the primary tumor and its PM. We assume that this phenomenon could be a result of genetic drift during tumor progression

There are two genetic "supergroups" in RCCs: the Krebs cycle group and the mTOR/ TSC group. CCRCC is by far the most common example of the Krebs cycle group, whereas the mTOR/TSC group includes a number of newly recognized novel tumors such as eosinophilic solid and cystic RCC (ESC-RCC), eosinophilic vacuolated tumor (EVT), lowgrade oncocytic tumor (LOT), and RCC with prominent fibromyomatous stroma (RCC FMS), for which the mutation of TSC1, TSC2 and/or MTOR is typical [42].

The mTOR pathway is an intracellular signaling pathway important for regulating the cell cycle. The most common genes involved in the tumorigenesis of the mTOR pathway group are $T S C 1, T S C 2$, and MTOR.

The mutation of the TSC genes in CCRCC is unusual but has been documented. Pang et al. [43] reported a rare case of CCRCC with novel biallelic somatic mutations in TSC2. This was a case of a 14-year-old female with VHL syndrome, where histologic findings were typical of CCRCC morphology. In addition, immunohistochemical findings also showed immunohistochemical expression for keratin, vimentin, CD10, and RCC, with negative results for CA9, keratin 7 and TFE3 staining. In our series, one of our patients (patient 1) demonstrated an interesting combination of mutations of VHL and TSC1 in the $\mathrm{PM}$, whereas we did not observe this phenomenon in the primary tumor. In the second patient, we verified a combination of VHL and PTEN mutations in the primary tumor and both metastases. In our third patient, the primary tumor showed a combination of TSC1, CUL3, DOT1L and SETD2 gene mutations (but not BAP1), whereas the PM had the same genetic mutations plus BAP1 mutation. This patient had metastatic disease at multiple sites post-surgery with disease progression. These molecular genetic findings indicate that in metastatic lesions, subclonal driver mutations are potentially responsible for spread and possible treatment failure. Such driver mutations were potentially missed due to sampling error or a lower number in samples analyzed by bulk sequencing. Another explanation might be the development of driver mutations over the course of the treatment. Current evidence suggests that treatment resistance and / or failure is caused by the resistant subclones, which were not targeted by the initial treatment [37]. We believe that optimizing the sampling approach in the metastatic setting, including the biopsy of newly developed 
metastatic CCRCC lesions, is important and can aid in effective therapeutic regimens due to the possible continued propagation of subclones.

One of the important novel renal entities in the differential diagnosis of CCRCC is RCC FMS [42]. Recognizing RCC FMS not only has academic value, but it also carries potential clinical implications and therapeutic management. Based on limited clinical data, these tumors tend to behave in an indolent fashion in most cases. In the largest cohort study of RCC FMS published to date [44], no evidence of recurrence or progression after surgical removal was documented. RCC FMS was included in the 2016 WHO classification of renal tumors as an emerging/provisional entity as "RCC with (angio) leiomyomatous stroma" [2]. However, distinct diagnostic criteria were not defined by the WHO classification. In the Genitourinary Pathology Society (GUPS) update review paper, the diagnostic histologic criteria for this distinct subtype of RCC have recently been established [42]. Tumors are composed of invariably voluminous epithelial clear cell components, which are typically diffusely positive for keratin 7 and of fibroleiomyomatous stroma. In this type of RCC, recurrent mutations involving the genes of the TSC/MTOR pathway were found. A subset of tumors with almost identical morphologic features showed mutations involving ELOC (also referred to as TCEB1), typically associated with the monosomy of chromosome 8 [44]. Both tumor subtypes lack VHL or chromosome 3p abnormalities [42,44]. In fact, it is not clear whether TSC/MTOR and ELOC mutated RCC with fibromyomatous stroma are two different tumor types, or just part of the molecular genetic variability within one tumor entity. Recently, one tumor with confirmed monosomy 8 and ELOC deletion as well as a TSC1 mutation was documented [32,44].

RCC FMS are suggested to be more frequently sporadic; however, identical tumors were documented in patients with TSC. However, although the duration of the followup period is limited, most RCC FMS with TSC/MTOR mutations have demonstrated an indolent biological behavior [44]. However, lymph node metastases have been reported in rare cases associated with TSC recently. Although the initial report on ELOC (TCEB1)associated RCC FMS suggested indolent behavior, an aggressive clinical course was recently described [45].

\section{Conclusions}

CCRCC are highly heterogeneous tumors, with complex molecular profiles both in the primary and metastatic settings. Tumor mutational profiles can be different not only between primary and metastatic tumors but also among multiple metastatic lesions themselves. It is evident that a one-size-fits-all approach is not optimal for treating advanced CCRCC and treatments need to be personalized. In this regard, optimizing tumor sampling and clinical management approaches in metastatic settings is crucial in order to identify subclonal mutations, which can ultimately lead to effective targeted therapies. The future of the successful personalized treatment and management of CCRCC is contingent upon a good understanding and accurate accounting for tumor heterogeneity.

The results of previously published studies and our own results show that CCRCC is a genetically heterogeneous tumor. The genetic background and mutation profile are highly variable within the primary tumor. However, data about the molecular genetic profile of the primary tumor and multiple metastases are very limited. It is apparent that the mutation profile can be different not only between the primary tumor and metastasis, but also among multiple metastases. Such important findings raise the question of the direct testing of each metastasis before the potential targeted therapy. Current clinical practice largely reflects genetic changes in primary tumors only. Because current oncologic treatment is reserved mostly for unresectable primary tumors and metastatic disease, we believe that such findings may become of critical importance. 
Author Contributions: Methodology, K.P. (Kristyna Prochazkova), O.H., T.V., J.V. and V.T.; validation, T.V., O.H., K.M. and K.P. (Kristyna Prochazkova); formal analysis, O.H., K.P. (Kristyna Prochazkova) and T.V.; investigation, K.P. (Kristyna Prochazkova), O.H., T.V., J.V., N.P., J.R., K.P. (Kristyna Pivovarcikova), K.M. and M.S.; resources, K.P. (Kristyna Prochazkova), O.H., T.V., J.V. and V.T.; writing - original draft preparation, K.P. (Kristyna Prochazkova), O.H., T.V. and J.V.; writingreview and editing, K.P. (Kristyna Prochazkova), O.H., T.V., J.V. and V.T.; visualization, K.P. (Kristyna Prochazkova), O.H. and T.V.; supervision, O.H., S.R.W., M.M., R.A., M.H. and V.T.; project administration, K.P. (Kristyna Prochazkova), O.H., T.V., J.V. and V.T. All authors have read and agreed to the published version of the manuscript.

Funding: This research was funded by the grant SVV-2020-2022 No 260539, by the Charles University Research Fund (Progres Q39), the grant of Ministry of Health of the Czech Republic - Conceptual Development of Research Organization (Faculty Hospital in Pilsen-FNPI 00669806).

Institutional Review Board Statement: All procedures performed in studies involving human participants were in accordance with the ethical standards of the institutional and/or national research committee and with the 1964 Helsinki declaration and its later amendments or comparable ethical standards.

Informed Consent Statement: Informed consent was obtained from all subjects involved in the study.

Data Availability Statement: Data is contained within the article.

Acknowledgments: The work was supported by the grant SVV-2020-2022 No 260539, by the Charles University Research Fund (Progres Q39), the grant of Ministry of Health of the Czech RepublicConceptual Development of Research Organization (Faculty Hospital in Pilsen-FNPI 00669806).

Conflicts of Interest: The authors declare no conflict of interest.

\section{References}

1. López, J.I. Renal Tumors with Clear Cells. A Review. Pathol. Res. Pract. 2013, 209, 137-146. [CrossRef] [PubMed]

2. Moch, H.; Humphrey, P.H.; Ulbright, T.M.; Reuter, V.E. (Eds.) WHO Classification of Tumours of the Urinary System and Male Genital Organs, 4th ed.; IARC: Lyon, France, 2016; 356p.

3. Ljungberg, B.; Bensalah, K.; Canfield, S.; Dabestani, S.; Hofmann, F.; Hora, M.; Kuczyk, M.A.; Lam, T.; Marconi, L.; Merseburger, A.S.; et al. EAU Guidelines on Renal Cell Carcinoma: 2014 Update. Eur. Urol. 2015, 67, 913-924. [CrossRef] [PubMed]

4. Procházková, K.; Vodička, J.; Fichtl, J.; Krákorová, G.; Šebek, J.; Roušarová, M.; Hošek, P.; Brookman May, S.D.; Hes, O.; Hora, M.; et al. Outcomes for Patients after Resection of Pulmonary Metastases from Clear Cell Renal Cell Carcinoma: 18 Years of Experience. Urol. Int. 2019, 103, 297-302. [CrossRef] [PubMed]

5. López, J.I.; Angulo, J.C. Pathological Bases and Clinical Impact of Intratumor Heterogeneity in Clear Cell Renal Cell Carcinoma. Curr. Urol. Rep. 2018, 19, 3. [CrossRef]

6. López, J.I.; Cortés, J.M. Multisite Tumor Sampling: A New Tumor Selection Method to Enhance Intratumor Heterogeneity Detection. Hum. Pathol. 2017, 64, 1-6. [CrossRef] [PubMed]

7. Cortés, J.M.; de Petris, G.; López, J.I. Detection of Intratumor Heterogeneity in Modern Pathology: A Multisite Tumor Sampling Perspective. Front. Med. 2017, 4, 25. [CrossRef]

8. Gonzalez, M.L.; Alaghehbandan, R.; Pivovarcikova, K.; Michalova, K.; Rogala, J.; Martinek, P.; Foix, M.P.; Mundo, E.C.; Comperat, E.; Ulamec, M.; et al. Reactivity of CK7 across the Spectrum of Renal Cell Carcinomas with Clear Cells. Histopathology 2019, 74, 608-617. [CrossRef]

9. Gerlinger, M.; Rowan, A.J.; Horswell, S.; Math, M.; Larkin, J.; Endesfelder, D.; Gronroos, E.; Martinez, P.; Matthews, N.; Stewart, A.; et al. Intratumor Heterogeneity and Branched Evolution Revealed by Multiregion Sequencing. N. Engl. J. Med. 2012, 366, 883-892. [CrossRef]

10. Marco Gerlinger, Stuart Horswell, James Larkin, Andrew J Rowan, Max P Salm, Ignacio Varela, Rosalie Fisher, Nicholas McGranahan, Nicholas Matthews, Claudio R Santos, Pierre Martinez, Benjamin Phillimore, Sharmin Begum, Adam Rabinowitz, Bradley Spencer-Dene, Sakshi Gulati, Paul A Bates, Gordon Stamp, Lisa Pickering, Martin Gore, David L Nicol, Steven Hazell, P Andrew Futreal, Aengus Stewart, Charles Swanton Genomic Architecture and Evolution of Clear Cell Renal Cell Carcinomas Defined by Multiregion Sequencing. Nat. Genet. 2014, 46, 225-233. [CrossRef]

11. Eckel-Passow, J.E.; Serie, D.J.; Cheville, J.C.; Ho, T.H.; Kapur, P.; Brugarolas, J.; Thompson, R.H.; Leibovich, B.C.; Kwon, E.D.; Joseph, R.W.; et al. BAP1 and PBRM1 in Metastatic Clear Cell Renal Cell Carcinoma: Tumor Heterogeneity and Concordance with Paired Primary Tumor. BMC Urol. 2017, 17, 19. [CrossRef] 
12. Brooks, S.A.; Brannon, A.R.; Parker, J.S.; Fisher, J.C.; Sen, O.; Kattan, M.W.; Hakimi, A.A.; Hsieh, J.J.; Choueiri, T.K.; Tamboli, P.; et al. ClearCode34: A Prognostic Risk Predictor for Localized Clear Cell Renal Cell Carcinoma. Eur. Urol. 2014, 66, 77-84. [CrossRef] [PubMed]

13. A Rose Brannon, Anupama Reddy, Michael Seiler, Alexandra Arreola, Dominic T Moore, Raj S Pruthi, Eric M Wallen, Matthew E Nielsen, Huiqing Liu, Katherine L Nathanson, Börje Ljungberg, Hongjuan Zhao, James D Brooks, Shridar Ganesan, Gyan Bhanot, W Kimryn Rathmell Molecular Stratification of Clear Cell Renal Cell Carcinoma by Consensus Clustering Reveals Distinct Subtypes and Survival Patterns. Genes Cancer 2010, 1, 152-163. [CrossRef]

14. Serie, D.J.; Joseph, R.W.; Cheville, J.C.; Ho, T.H.; Parasramka, M.; Hilton, T.; Thompson, R.H.; Leibovich, B.C.; Parker, A.S.; EckelPassow, J.E. Clear Cell Type A and B Molecular Subtypes in Metastatic Clear Cell Renal Cell Carcinoma: Tumor Heterogeneity and Aggressiveness. Eur. Urol. 2017, 71, 979-985. [CrossRef] [PubMed]

15. Williamson, S.R.; Halat, S.; Eble, J.N.; Grignon, D.J.; Lopez-Beltran, A.; Montironi, R.; Tan, P.-H.; Wang, M.; Zhang, S.; MacLennan, G.T.; et al. Multilocular Cystic Renal Cell Carcinoma: Similarities and Differences in Immunoprofile Compared With Clear Cell Renal Cell Carcinoma. Am. J. Surg. Pathol. 2012, 36, 1425-1433. [CrossRef]

16. Chen, Y.-B.; Xu, J.; Skanderup, A.J.; Dong, Y.; Brannon, A.R.; Wang, L.; Won, H.H.; Wang, P.I.; Nanjangud, G.J.; Jungbluth, A.A.; et al. Molecular Analysis of Aggressive Renal Cell Carcinoma with Unclassified Histology Reveals Distinct Subsets. Nat. Commun. 2016, 7, 13131. [CrossRef]

17. Williamson, S.R.; Grignon, D.J.; Cheng, L.; Favazza, L.; Gondim, D.D.; Carskadon, S.; Gupta, N.S.; Chitale, D.A.; KalyanaSundaram, S.; Palanisamy, N. Renal Cell Carcinoma With Chromosome 6p Amplification Including the TFEB Gene: A Novel Mechanism of Tumor Pathogenesis? Am. J. Surg. Pathol. 2017, 41, 287-298. [CrossRef]

18. Klatte, T.; Said, J.W.; Seligson, D.B.; Rao, P.N.; de Martino, M.; Shuch, B.; Zomorodian, N.; Kabbinavar, F.F.; Belldegrun, A.S.; Pantuck, A.J. Pathological, Immunohistochemical and Cytogenetic Features of Papillary Renal Cell Carcinoma with Clear Cell Features. J. Urol. 2011, 185, 30-36. [CrossRef]

19. Cancer Genome Atlas Research Network Comprehensive Molecular Characterization of Clear Cell Renal Cell Carcinoma. Nature 2013, 499, 43-49. [CrossRef]

20. Brierley, J.D.; Gospodarowicz, M.K. Wittekind Christian. In TNM Classification of Malignant Tumours, 8th ed.; Wiley-Blackwell: Hoboken, NJ, USA, 2016; ISBN 978-1-119-26357-9.

21. Farcaş, M.; Gatalica, Z.; Trpkov, K.; Swensen, J.; Zhou, M.; Alaghehbandan, R.; Williamson, S.R.; Magi-Galluzzi, C.; Gill, A.J.; Tretiakova, M.; et al. Eosinophilic Vacuolated Tumor (EVT) of Kidney Demonstrates Sporadic TSC/MTOR Mutations: Next-Generation Sequencing Multi-Institutional Study of 19 Cases. Mod. Pathol. 2021. [CrossRef]

22. Pestinger, V.; Smith, M.; Sillo, T.; Findlay, J.M.; Laes, J.-F.; Martin, G.; Middleton, G.; Taniere, P.; Beggs, A.D. Use of an Integrated Pan-Cancer Oncology Enrichment Next-Generation Sequencing Assay to Measure Tumour Mutational Burden and Detect Clinically Actionable Variants. Mol. Diagn. Ther. 2020, 24, 339-349. [CrossRef]

23. Na, K.; Kim, H.-S.; Shim, H.S.; Chang, J.H.; Kang, S.-G.; Kim, S.H. Targeted Next-Generation Sequencing Panel (TruSight Tumor 170) in Diffuse Glioma: A Single Institutional Experience of 135 Cases. J. Neuro-Oncol. 2019, 142, 445-454. [CrossRef] [PubMed]

24. Petersson, F.; Martinek, P.; Vanecek, T.; Pivovarcikova, K.; Peckova, K.; Ondic, O.; Perez-Montiel, D.; Skenderi, F.; Ulamec, M.; Nenutil, R.; et al. Renal Cell Carcinoma With Leiomyomatous Stroma: A Group of Tumors With Indistinguishable Histopathologic Features, But 2 Distinct Genetic Profiles: Next-Generation Sequencing Analysis of 6 Cases Negative for Aberrations Related to the VHL Gene. Appl. Immunohistochem. Mol. Morphol. 2018, 26, 192-197. [CrossRef] [PubMed]

25. Kojima, F.; Bulimbasic, S.; Alaghehbandan, R.; Martinek, P.; Vanecek, T.; Michalova, K.; Pivovarcikova, K.; Michal, M.; Hora, M.; Murata, S.; et al. Clear Cell Renal Cell Carcinoma with Paneth-like Cells: Clinicopathologic, Morphologic, Immunohistochemical, Ultrastructural, and Molecular Analysis of 13 Cases. Ann. Diagn. Pathol. 2019, 41, 96-101. [CrossRef]

26. Ricketts, C.J.; De Cubas, A.A.; Fan, H.; Smith, C.C.; Lang, M.; Reznik, E.; Bowlby, R.; Gibb, E.A.; Akbani, R.; Beroukhim, R.; et al. The Cancer Genome Atlas Comprehensive Molecular Characterization of Renal Cell Carcinoma. Cell Rep. 2018, 23, 313-326.e5. [CrossRef]

27. Nickerson, M.L.; Jaeger, E.; Shi, Y.; Durocher, J.A.; Mahurkar, S.; Zaridze, D.; Matveev, V.; Janout, V.; Kollarova, H.; Bencko, V.; et al. Improved Identification of von Hippel-Lindau Gene Alterations in Clear Cell Renal Tumors. Clin. Cancer Res. 2008, 14, 4726-4734. [CrossRef]

28. Zbar, B.; Brauch, H.; Talmadge, C.; Linehan, M. Loss of Alleles of Loci on the Short Arm of Chromosome 3 in Renal Cell Carcinoma. Nature 1987, 327, 721-724. [CrossRef] [PubMed]

29. Mitchell, T.J.; Turajlic, S.; Rowan, A.; Nicol, D.; Farmery, J.H.R.; O’Brien, T.; Martincorena, I.; Tarpey, P.; Angelopoulos, N.; Yates, L.R.; et al. Timing the Landmark Events in the Evolution of Clear Cell Renal Cell Cancer: TRACERx Renal. Cell 2018, 173, 611-623.e17. [CrossRef]

30. Choueiri, T.K.; Kaelin, W.G. Targeting the HIF2-VEGF Axis in Renal Cell Carcinoma. Nat. Med. 2020, 26, 1519-1530. [CrossRef]

31. Brugarolas, J. Molecular Genetics of Clear-Cell Renal Cell Carcinoma. J. Clin. Oncol. 2014, 32, 1968-1976. [CrossRef]

32. Hakimi, A.A.; Tickoo, S.K.; Jacobsen, A.; Sarungbam, J.; Sfakianos, J.P.; Sato, Y.; Morikawa, T.; Kume, H.; Fukayama, M.; Homma, Y.; et al. TCEB1-Mutated Renal Cell Carcinoma: A Distinct Genomic and Morphological Subtype. Mod. Pathol. 2015, 28, 845-853. [CrossRef] 
33. Favazza, L.; Chitale, D.A.; Barod, R.; Rogers, C.G.; Kalyana-Sundaram, S.; Palanisamy, N.; Gupta, N.S.; Williamson, S.R. Renal Cell Tumors with Clear Cell Histology and Intact VHL and Chromosome 3p: A Histological Review of Tumors from the Cancer Genome Atlas Database. Mod. Pathol. 2017, 30, 1603-1612. [CrossRef]

34. Turajlic, S.; Xu, H.; Litchfield, K.; Rowan, A.; Horswell, S.; Chambers, T.; O’Brien, T.; Lopez, J.I.; Watkins, T.B.K.; Nicol, D.; et al. Deterministic Evolutionary Trajectories Influence Primary Tumor Growth: TRACERx Renal. Cell 2018, 173, 595-610.e11. [CrossRef]

35. Cai, Q.; Christie, A.; Rajaram, S.; Zhou, Q.; Araj, E.; Chintalapati, S.; Singla, N.; Cadeddu, J.; Margulis, V.; Pedrosa, I.; et al. Corrigendum to "Ontological Analyses Reveal Clinically-Significant Clear Cell Renal Cell Carcinoma Subtypes with Convergent Evolutionary Trajectories into an Aggressive Type" [EBioMedicine 51 (2020) 102526]. EBioMedicine 2020, 55, 102707. [CrossRef] [PubMed]

36. Peña-Llopis, S.; Christie, A.; Xie, X.-J.; Brugarolas, J. Cooperation and Antagonism among Cancer Genes: The Renal Cancer Paradigm. Cancer Res. 2013, 73, 4173-4179. [CrossRef] [PubMed]

37. Beksac, A.T.; Paulucci, D.J.; Blum, K.A.; Yadav, S.S.; Sfakianos, J.P.; Badani, K.K. Heterogeneity in Renal Cell Carcinoma. Urol. Oncol. Semin. Orig. Investig. 2017, 35, 507-515. [CrossRef]

38. Brugarolas, J.; Rajaram, S.; Christie, A.; Kapur, P. The Evolution of Angiogenic and Inflamed Tumors: The Renal Cancer Paradigm. Cancer Cell 2020, 38, 771-773. [CrossRef]

39. Wang, T.; Lu, R.; Kapur, P.; Jaiswal, B.S.; Hannan, R.; Zhang, Z.; Pedrosa, I.; Luke, J.J.; Zhang, H.; Goldstein, L.D.; et al. An Empirical Approach Leveraging Tumorgrafts to Dissect the Tumor Microenvironment in Renal Cell Carcinoma Identifies Missing Link to Prognostic Inflammatory Factors. Cancer Discov. 2018, 8, 1142-1155. [CrossRef] [PubMed]

40. Turajlic, S.; Xu, H.; Litchfield, K.; Rowan, A.; Chambers, T.; Lopez, J.I.; Nicol, D.; O’Brien, T.; Larkin, J.; Horswell, S.; et al. Tracking Cancer Evolution Reveals Constrained Routes to Metastases: TRACERx Renal. Cell 2018, 173, 581-594.e12. [CrossRef] [PubMed]

41. Motzer, R.J.; Banchereau, R.; Hamidi, H.; Powles, T.; McDermott, D.; Atkins, M.B.; Escudier, B.; Liu, L.-F.; Leng, N.; Abbas, A.R.; et al. Molecular Subsets in Renal Cancer Determine Outcome to Checkpoint and Angiogenesis Blockade. Cancer Cell 2020, 38, 803-817.e4. [CrossRef]

42. Trpkov, K.; Williamson, S.R.; Gill, A.J.; Adeniran, A.J.; Agaimy, A.; Alaghehbandan, R.; Amin, M.B.; Argani, P.; Chen, Y.-B.; Cheng, L.; et al. Novel, Emerging and Provisional Renal Entities: The Genitourinary Pathology Society (GUPS) Update on Renal Neoplasia. Mod. Pathol. 2021, 34, 1167-1184. [CrossRef]

43. Pang, J.; Wang, L.; Xu, J.; Xie, Q.; Liu, Q.; Tong, D.; Liu, G.; Huang, Y.; Yang, X.; Pan, J.; et al. A Renal Cell Carcinoma with Biallelic Somatic TSC2 Mutation: Clinical Study and Literature Review. Urology 2019, 133, 96-102. [CrossRef] [PubMed]

44. Shah, R.B.; Stohr, B.A.; Tu, Z.J.; Gao, Y.; Przybycin, C.G.; Nguyen, J.; Cox, R.M.; Rashid-Kolvear, F.; Weindel, M.D.; Farkas, D.H.; et al. "Renal Cell Carcinoma With Leiomyomatous Stroma" Harbor Somatic Mutations of TSC1, TSC2, MTOR, and/or ELOC (TCEB1): Clinicopathologic and Molecular Characterization of 18 Sporadic Tumors Supports a Distinct Entity. Am. J. Surg. Pathol. 2020, 44, 571-581. [CrossRef] [PubMed]

45. DiNatale, R.G.; Gorelick, A.N.; Makarov, V.; Blum, K.A.; Silagy, A.W.; Freeman, B.; Chowell, D.; Marcon, J.; Mano, R.; Sanchez, A.; et al. Putative Drivers of Aggressiveness in TCEB1-Mutant Renal Cell Carcinoma: An Emerging Entity with Variable Clinical Course. Eur. Urol. Focus 2021, 7, 381-389. [CrossRef] [PubMed] 